\title{
Electrochemical detection of white spot syndrome virus with a silicone rubber disposable electrode composed of graphene quantum dots and gold
} nanoparticle-embedded polyaniline nanowires

\author{
Kenshin Takemura', Jun Satoh², Jirayu Boonyakida', Sungjo Park ${ }^{3}$, Ankan Dutta Chowdhury ${ }^{4}$
} and Enoch Y. Park ${ }^{1,4^{*}}$ (1)

\begin{abstract}
Background: With the enormous increment of globalization and global warming, it is expected that the number of newly evolved infectious diseases will continue to increase. To prevent damage due to these infections, the development of a diagnostic method for detecting a virus with high sensitivity in a short time is highly desired. In this study, we have developed a disposable electrode with high-sensitivity and accuracy to evaluate its performances for several target viruses.

Results: Conductive silicon rubber (CSR) was used to fabricate a disposable sensing matrix composed of nitrogen and sulfur-co-doped graphene quantum dots (N,S-GQDs) and a gold-polyaniline nanocomposite (AuNP-PAni). A specific anti-white spot syndrome virus (WSSV) antibody was conjugated to the surface of this nanocomposite, which was successfully applied for the detection of WSSV over a wide linear range of concentration from $1.45 \times 10^{2}$ to $1.45 \times 10^{5} \mathrm{DNA}$ copies $/ \mathrm{ml}$, with a detection limit as low as $48.4 \mathrm{DNA}$ copies $/ \mathrm{ml}$.

Conclusion: The engineered sensor electrode can retain the detection activity up to 5 weeks, to confirm its longterm stability, required for disposable sensing applications. This is the first demonstration of the detection of WSSV by a nanofabricated sensing electrode with high sensitivity, selectivity, and stability, providing as a potential diagnostic tool to monitor WSSV in the aquaculture industry.
\end{abstract}

Keywords: White spot syndrome virus, Electrochemical virus detection, Disposable electrode, Polyaniline, Gold nanoparticle, Graphene quantum dots

\footnotetext{
*Correspondence: park.enoch@shizuoka.ac.jp

${ }^{4}$ Laboratory of Biotechnology, Research Institute of Green Science

and Technology, Shizuoka University, 836 Ohya, Suruga-ku,

Shizuoka 422-8529, Japan

Full list of author information is available at the end of the article
}

\section{Background}

White spot syndrome virus (WSSV) infects shrimp and causes white spot disease (WSD), which is considered one of the most lethal virus pathogens in cultured shrimp [1]. WSSV was initially discovered in Taiwan and spread quickly to the entire world $[2,3]$. The infection reaches a cumulative mortality of up to $100 \%$ within $10 \mathrm{~d}$, causing rapid economic damage in fishery industries [4].

(c) The Author(s) 2020. This article is licensed under a Creative Commons Attribution 4.0 International License, which permits use, sharing, adaptation, distribution and reproduction in any medium or format, as long as you give appropriate credit to the original author(s) and the source, provide a link to the Creative Commons licence, and indicate if changes were made. The images or other third party material in this article are included in the article's Creative Commons licence, unless indicated otherwise in a credit line to the material. If material is not included in the article's Creative Commons licence and your intended use is not permitted by statutory regulation or exceeds the permitted use, you will need to obtain permission directly from the copyright holder. To view a copy of this licence, visit http://creativeco mmons.org/licenses/by/4.0/. The Creative Commons Public Domain Dedication waiver (http://creativecommons.org/publicdomain/ zero/1.0/) applies to the data made available in this article, unless otherwise stated in a credit line to the data. 
Recently, India reported an approximately several million US\$ loss per year due to WSD [5]. WSSV spreads by vertical infection or cannibalism between shrimp and other invertebrate aquatic organisms, such as crab and crayfish [6], with a high mortality rate; a promising rapid detection method needs to be developed to prevent the onset of this epidemic.

Vaccination is always the most useful method for solving any viral infection. Using WSSV envelope proteins (e.g., VP19 and VP28), a few attempts to induce an immune response and protect shrimp from WSSV infection have already been reported [7-9]. However, the outcome of the vaccination method is still poor considering its practical use. To avoid the risk of WSD in shrimp farming, the only way is to quickly identify the infected shrimp and isolate it from the farm. Current methods for detecting WSSV rely on PCR techniques using viral DNAs or protein assays using a specific antibody $[10,11]$. The limit of detection (LOD) is a few hundred DNA copies/ml within 4 to $12 \mathrm{~h}$ [12-14]. Likewise, dot blots, lateral flow assay, and enzyme-linked immunosorbent assay (ELISA) using antigen-antibody reactions have been generally used for the detection of WSSV envelope proteins [15-19]. The LOD is in the range of 1000 DNA copies/ml using the lateral flow assay and $120 \mathrm{ng} / \mathrm{ml}$ using ELISA. However, the availability of diagnostic PCR assays for use in aquaculture remains limited because they are costly and require highly skilled operators.

On the other hand, antigen detection methods are useful for rapid clinical diagnosis of viral infection [20] but fail to attain the desired sensitivity. In a recent study, a fluorescence resonance energy transfer (FRET)-based detection technique using graphene oxide detected WSSV with an LOD of 10 DNA copies/ml [21]. In another study, WSSV was detected with an LOD of $1.36 \times 10^{3}$ DNA copies/ $\mu \mathrm{l}$ using the electrochemical property of methylene blue conjugated to graphene oxide [22]. Although a few reports on WSSV detection with low sensitivity have been published, in terms of their stability and reliability, these sensors are not suitable for real-time applications.

Nanomaterials with unique physical, optical and electrochemical properties [23-28] have shown successful detection of viruses with high sensitivity [29-31]. Previously, we demonstrated hepatitis $\mathrm{E}$ virus detection with a fabricated biosensor electrode constituted by specific antibodies and nanomaterials based on an engineered impedimetric process [32]. In this report, we have developed a conducting sensor matrix fabricated with polyaniline, nitrogen and sulfur-codoped graphene quantum dots (N,S-GQDs) and gold nanoparticles (AuNPs) for the detection of WSSV. In an interfacial reaction, AuNPs embedded in polyaniline nanowires (AuNP-PAni) were synthesized and bound to N,S-GQDs via the Au-S affinity because the interaction between PAni and AuNPs provides excellent conductivity to the N,S-GQD@AuNPPAni nanocomposite [33, 34]. The nanocomposite was deposited on a finely electropolymerized polyanilinecoated conductive silicon rubber (CSR) surface. The coating of the Ab-N,S-GQD@AuNP-PAni nanocomposite on the surface of the CSR significantly improved the conductivity of the CSR. On the other hand, the conductivity significantly decreased after capturing WSSV due to the increased charge transfer resistance $\left(R_{c t}\right)$ of the $A b$ N,S-GQD@AuNP-PAni-coated electrode. This disposable electrode demonstrates the capability for detecting WSSV over a wide linear range with high specificity and sensitivity. The sensor stability was also tested over more than one month to confirm its applicability for on-site virus detection. Thus, our fabricated disposable electrode modified by a simple and uniform nanocomposite coating aiming for more convenient use allows accurate WSSV detection and is applicable to sensing WSSV in the aquaculture industry.

\section{Materials and methods \\ Materials}

PBS buffer, polyoxyethylene (20) sorbitan monolaurate (Tween 20), sodium acetate, hydrogen peroxide, sulfuric acid, methanol, potassium hydroxide $(\mathrm{KOH})$, chloroform and acetone were purchased from Wako Pure Chemical Ind. Ltd. (Osaka, Japan). $\mathrm{HAuCl}_{4}, \mathrm{~N}-(3-$ dimethylaminopropyl)- $\mathrm{N}^{\prime}$-ethylcarbodiimide hydrochloride (EDC), N-hydroxysuccinimide (NHS), and bovine serum albumin (BSA) were purchased from Sigma Aldrich Co., LLC (Saint Louis, MO, USA). Oleic acid was purchased from Nacalai Tesque Inc. (Kyoto, Japan). Tetramethylbenzidine (TMBZ) was purchased from Dojindo Laboratories (Kumamoto, Japan). Anti-WSSV VP28 antibody [ab26935] and a mouse monoclonal antibody [B219M] were purchased from Abcam Inc. (Cambridge, UK). Anti-HA antibody (New Caledonia/20/99) (H1N1) was purchased from Prospec-Tany Techno Gene Ltd. (Rehovot, Israel). Goat anti-rabbit IgG-HRP was purchased from Santa Cruz Biotechnology (CA, USA). Geno type 3 hepatitis E virus (HEV), rabbit anti-G3 HEV IgG antibody, and norovirus-like particle (NoV-LP) were provided by Dr Tian-Cheng Li (National Institute of Infectious Diseases, Japan). Zika virus (ZIKV) strain PRVABC-59 was provided by Professor Kouichi Morita (Institute of Tropical Medicine, Nagasaki University, Japan).

\section{Equipment}

UV/vis absorption and fluorescence emission measurements were carried out using a filter-based multimode 
microplate reader (Infinite M200; TECAN, Ltd, Männedorf, Switzerland). Transmission electron microscopy (TEM) images were obtained with a TEM system (JEM-2100F; JEOL, Ltd., Tokyo, Japan) operated at $100 \mathrm{kV}$. Scanning electron microscopy (SEM) images were obtained with SEM equipment (JSM-6510LV; JEOL, Tokyo, Japan). A General Laboratory Homogenizer (OMNI International, USA) was used for WSSV sample preparation from shrimp. Western blotting was carried out using a Trans-Blot-SD (Bio-Rad, Japan) and transferred by using Immobilon ECL Ultra Western HRP Substrate (Merck, Japan). The membrane after western blotting was filmed by a VersaDoc 4000 MP (Bio-Rad, Japan). The centrifugation for virus sample collection proceeded using a Micro-cooled Centrifuge 3700 (KUBOTA, Japan). Powder X-ray diffraction (PXRD) analysis was carried out using a RINT ULTIMA XRD (Rigaku Co., Tokyo, Japan) with a Ni filter and a $\mathrm{Cu}-\mathrm{K} \alpha$ source. Data were collected over $2 \theta=5^{\circ}-60^{\circ}$ at a scan rate of $0.01^{\circ}$ step and $10 \mathrm{~s} /$ point. Fourier transform infrared spectroscopy (FTIR) was recorded on FT/ IR-6300 (JASCO, Japan). Zeta potential and dynamic light scattering (DLS) measurements were performed using a Zetasizer Nano series (Malvern Inst. Ltd., Malvern, UK). Conjugation of the Ab to the QDs and GNPs was confirmed with a plate reader (Bio-Rad, model 680, Hercules, USA). A high-resolution transmission electron microscopy (HRTEM) image was taken by a JEM$2100 \mathrm{~F}$ at $200 \mathrm{kV}$ (JEOL, Tokyo, Japan). Atomic force microscopy (AFM) analysis was achieved with a Nanoscope IV Pico Force Multimode atomic force microscope (Bruker, Santa Barbara, CA, USA) in contact mode [35]. Electrochemical cyclic voltammetry (CV) and electrochemical impedance spectroscopy (EIS) were carried out using an SP-150 (BioLogic Inc, Tokyo, Japan) in a conventional three-electrode cell consisting of platinum wire. Saturated $\mathrm{Ag} / \mathrm{AgCl}$ was used as an electrolyzer (EC frontier, Tokyo, Japan).

\section{Synthesis of the AuNP-PAni nanocomposite}

AuNP-PAni was synthesized using the interfacial polymerization method [34]. A $0.5 \mathrm{M}$ aniline monomer in toluene mixture was prepared as an organic phase, and $3 \mathrm{mM}$ $\mathrm{HAuCl}_{4}$ in $0.1 \mathrm{M} \mathrm{HCl}$ solution was slowly poured in as an aqueous phase to initiate the interfacial polymerization process. Polyaniline nanowires were gradually formed by oxidation of aniline into an aqueous phase, and the solution color became dark green within several minutes. At the same time, $\mathrm{HAuCl}_{4}$ was reduced to AuNPs and embedded within the polyaniline nanowires. The synthesized solution was centrifuged (room temperature, $5500 \times g$ ) and redispersed using ultrapure water for purification. This purification process was repeated 3 times.

\section{N,S-GQD preparation and conjugation of anti-WSSV VP28 antibody}

N,S-GQDs were synthesized using a hydrothermal system [36]. N,S-GQDs were quickly bonded with antiWSSV VP28 antibody (Ab) using EDC/NHS covalent chemistry [37]. In brief, $0.1 \mathrm{M}$ EDC was mixed with a solution containing $\mathrm{Ab} 5.1 \mu \mathrm{g}$, and EDC reacted with the carboxyl group of the $\mathrm{Ab}$ to create an active-ester intermediate within $30 \mathrm{~min}$ of stirring at $7{ }^{\circ} \mathrm{C}$. To generate amine reactivity of the amino group with the surface of the GQDs, $0.1 \mathrm{M} \mathrm{NHS}$ and $1 \mathrm{ml}$ of N,S-GQDs were added and continuously stirred at $7{ }^{\circ} \mathrm{C}$ over $16 \mathrm{~h}$. The reaction solution was dialyzed using a $1 \mathrm{kDa}$ dialysis bag to remove unreacted EDC and NHS. Finally, the solution of Ab-conjugated N,S-GQDs (Ab-N,S-GQDs) was preserved in 0.1 M PBS (pH 7.4) at $4{ }^{\circ} \mathrm{C}$ until use.

The conjugation of Abs to N,S-GQDs was confirmed using ELISA. Ab-conjugated N,S-GQDs were added to a polystyrene 96 -well plate $(100 \mu \mathrm{l})$ and incubated overnight at $4{ }^{\circ} \mathrm{C}$. As a negative control, $100 \mu \mathrm{l}$ of BSA was added to a separate well, and $100 \mu \mathrm{l}$ of $5 \%$ skim milk solution was added and applied as a blocking agent after washing 3 times with PBST (containing $1 \mathrm{ml}$ of Tween in $999 \mathrm{ml}$ of PBS buffer). After blocking, the 5\% skim milk was removed by washing 3 times with PBST. Anti-rabbit IgG-horseradish peroxidase was diluted to 1:4000 with $2 \% \mathrm{BSA}$, and $100 \mu \mathrm{l}$ of this solution was added to the well and incubated at ambient temperature for $1 \mathrm{~h}$. TMB $(100 \mu \mathrm{l})$, a chromogenic substrate, was added to the well as a coloring reagent, and the solution appeared blue due to the reaction. The reaction was then stopped by adding $50 \mu \mathrm{l}$ of $10 \% \mathrm{H}_{2} \mathrm{SO}_{4}$, which changed the color of the solution from blue to yellow. The absorbance of the solution was measured using a microplate reader at $450 \mathrm{~nm}$ with a reference filter of $655 \mathrm{~nm}$.

\section{Fabrication of the disposable electrode}

Nanocomposite deposition on the sensor electrode produced high conductivity to the electrodes. Ab-N,S-GQD solution was mixed with AuNP-PAni solution and stirring for $16 \mathrm{~h}$ at $7{ }^{\circ} \mathrm{C}$, where the Sulphur molecules, doped on N,S-GQD formed strong Au-S bonds with AuNPs via soft acid-soft base interaction.

In ultrapure water, $0.5 \mathrm{M}$ sulfuric acid and $0.1 \mathrm{M}$ aniline monomer were mixed for electrochemical deposition of polyaniline on conductive silicone rubber (CSR) by cyclic voltammetry $(\mathrm{CV})$ in a three-electrode system. The CV curve was recorded at a scan rate of $20 \mathrm{mV} / \mathrm{s}$ in a potential range of $0-1 \mathrm{~V}$ for 15 cycles. The backside of the CSR electrode was covered by nonconducting tape to protect the polyaniline coating on the other side. Then, $15 \mu \mathrm{l}$ of Ab-N,S-GQD@AuNP-PAni solution was dropcast on the polymerized CSR/PAni. The formation of the 
Ab-N,S-GQD@AuNP-PAni nanocomposite was characterized by TEM and XRD.

\section{WSSV collection and pretreatment}

A WSSV suspension was prepared according to a previously reported protocol [38]. In brief, the muscle tissue of moribund WSSV-infected shrimp was homogenized using GLH in $4 \times$ PBS volume, followed by centrifugation at $1000 \times g$ for $10 \mathrm{~min}$ at $4{ }^{\circ} \mathrm{C}$. The supernatant was then filtered through a $0.22 \mu \mathrm{m}$ cellulose acetate membrane. The filtrate containing WSSV was kept at $-80{ }^{\circ} \mathrm{C}$ before use in subsequent experiments.

\section{Detection of WSSV using the disposable electrode}

The WSSV solution was diluted in series from $1.0 \times 10^{9}$ DNA copies/ml to 10 DNA copies/ml using filtered $0.1 \mathrm{M}$ PBS. Ten microliters of WSSV solution was dropped on the disposable electrode and incubated for $10 \mathrm{~min}$ at room temperature. WSSV bound the anti-WSSV VP28 $\mathrm{Ab}$ on the surface of the WSSV that was conjugated to Ab-N,S-GQD because of the specific binding between anti-WSSV VP28 Ab and the VP28 of WSSV. The electrode was mildly washed by dipping it in PBST to remove unbound viruses and then placed in an electrolytic solution. The charge resistance value $\left(\mathrm{R}_{\mathrm{ct}}\right)$ on the electrode was measured in the potential electrochemical impedance spectroscopy (PEIS) mode with a sinusoidal amplitude of $5 \mathrm{mV}$ within a frequency range from $100 \mathrm{kHz}$ to $0.1 \mathrm{~Hz}$. The WSSV detection time using this disposable electrode was less than $15 \mathrm{~min}$. For comparison, their DNA copy numbers were measured according to standard RT-PCR [39].

\section{Western blot analysis of WSSV-VP28}

The resultant supernatants of WSSV were loaded on an $18 \%$ polyacrylamide gel under denatured conditions and transferred to a PVDF membrane using the Trans-Blot$\mathrm{SD}$ system for $1 \mathrm{~h}$ at $15 \mathrm{~mA}$. The membrane was then incubated in a blocking buffer $(5 \% \mathrm{w} / \mathrm{v}$ skim milk in TBS containing $0.1 \%$ Tween 20 [TBS-T]) for $1 \mathrm{~h}$ at room temperature, followed by washing the membrane with TBS-T 3 times for $5 \mathrm{~min}$. For protein detection, the membrane was incubated with a primary antibody, anti-WSSVVP28 rabbit monoclonal antibody (1:2000), overnight at $4{ }^{\circ} \mathrm{C}$ and washed with TBS-T, followed by incubation with a secondary antibody (anti-IgG [Rabbit] pAb-HRP [1:10000]) for $1 \mathrm{~h}$ at room temperature. The immunoreactive bands were visualized and filmed for analysis.

\section{Selectivity and stability of the disposable electrode}

IFV A (H1N1) and hepatitis E virus (HEV), various solution containing impurity, metal ions were used for the selectivity test of the Ab-N,S-GQD@AuNP-PAni/CSR electrode. In addition, solutions containing foreign substances was used to evaluate the practicability of the sensor in accordance with the cited references [40-42]. To confirm the stability, the disposable electrodes were preserved at $4{ }^{\circ} \mathrm{C}$ for $60 \mathrm{~d}$, testing the performance of the electrodes every week.

\section{Results and discussion}

\section{Characterization of Ab-N,S-GQD@AuNP-PAni on the CSR}

The AuNP-PAni nanocomposite was deposited on a finely electropolymerized polyaniline-coated CSR electrode to form a AuNP-PAni-PAni/CSR electrode. The Ab-N,S-GQDs were then bound to the AuNP-PAni to prepare Ab-N,S-GQD@AuNP-PAni-PAni/CSR as shown in Scheme 1. In the N,S-GQD@AuNP-PAni nanocomposite, the AuNPs play an anchoring role between the N,S-GQDs and the polyaniline wires via soft acid-soft base interactions between $\mathrm{Au}$ and $\mathrm{S}$. According to the TEM analysis, the diameter of the AuNP-PAni nanowires was 50-70 nm, where the AuNPs dispersed evenly in the polymeric chain, and their size ranged from 6-14 nm (Fig. 1a). The HRTEM image of the N,S-GQD@AuNPPAni nanocomposite shows two distinct fringe patterns (Fig. 1b) of two crystalized structures of N,S-GQDs, and the AuNPs are deciphered as shown in Fig. 1c. The characteristic fringe of $0.24 \mathrm{~nm}$ for AuNPs is deciphered to the adjacent position of N,S-GQDs with a fringe distance of $0.21 \mathrm{~nm}$, which is the distinctive fringe of the carbon lattice (Fig. 1c) [43, 44].

The structural properties of the N,S-GQD@AuNPPAni nanocomposite were analyzed by XRD, as shown in Fig. 1d. PAni clearly revealed specific peak at $2 \theta=26.0^{\circ}$ corresponding to the (021). AuNP peaks are observed in the nanocomposite along with the characteristic peaks at $2 \theta=23.6^{\circ}, 25.5^{\circ}, 28.2^{\circ}, 38.2^{\circ}, 44.3^{\circ}, 64.4^{\circ}$, and $78.2^{\circ}$ corresponding to the (100), (110), (111), (200), (220), and (221) planes, respectively (Fig. 1d) [45, 46]. After the N,SGQDs were bound, the nanocomposite showed similar peaks and intensities, indicating that the attachment of GQDs does not induce any structural lattice changes of the AuNPs [47]. The graphitic layer shows a hump at $24^{\circ}$ in the XRD spectrum, which is completely masked by the high-intensity peaks of AuNPs. To show the binding of N,S-GQD to AuNP-PAni, FT-IR analysis was performed. Similar peaks for PAni and AuNP-PAni were observed in addition to a characteristic peak at $2570 \mathrm{~cm}^{-1}$ for the thiol group of N,S-GQDs. A strong peak at $3300-3400 \mathrm{~cm}^{-1}$ was also observed for the amino or hydroxyl group as expected (Additional file 1: Fig. S1). These peaks indicate the attachment of N,S-GQDs on the AuNP-PAni nanocomposites. The conjugation of antibody was confirmed by ELISA as the absorbance value of the Ab-N,S-GQDs 
significantly increased compared with bare N,S-GQDs (Fig. 1e).

The electrochemical properties of the CSR electrode surface were measured by cyclic voltammetry. Despite the functional conducting matrix, the charge storage capacity of the bare CSR is very low, and the bare CSR shows a narrow curve, which significantly increases after the polyaniline coating (Fig. 1f). Additionally, a redox peak of polyaniline appears at $+0.8 /+0.1 \mathrm{~V}$, indicating the formation of the emeraldine salt of polyaniline [48]. After the formation of the nanocomposite, the conductivity of the disposable electrode shows an enhancement of the current density, indicating successful preparation of the sensor electrode for electrochemical analysis.

\section{Optimization of the sensing performance of Ab-N,S-GQD@ AuNP-PAni}

The nanocomposite layer's thickness on the CSR matrix is an essential parameter for maintaining the disposable electrode's reproducibility. The thickness of the base matrix of polyaniline is directly proportional to the CV cycle number in the electropolymerization step. The resistance of the polyaniline-coated CSR becomes the lowest at 15 cycles because of the emeraldine salt formation of polyaniline (green). However, at 20 cycles or more, the redox reactions showed a decrease in conductivity due to predominantly overoxidized formation of pernigraniline of polyaniline (blue) (Additional file 1:
Fig S2). Furthermore, after the electrolytic polymerization, SEM analysis of the CSRs showed that the polyaniline layer's thickness became thicker with the increasing number of cycles (Additional file 1: Fig. S3A-C). A thick polyaniline layer can lead to a reverse effect on the conductivity of CSR. The 15 cycled PAni/ CSR stability was tested over 50 cycles, showing excellent stability under the optimized polyaniline layer (Additional file 1: Fig. S4). The electrochemical properties of the CSRs did not change significantly after incubation in buffer for $24 \mathrm{~h}$, confirming its stability as electrodes for sensor preparation (Additional file 1: Fig. S5). The thickness of the layer was further characterized by SEM and AFM. The bare CSR with a smooth surface becomes rough with coating of polymerized polyaniline (Fig. 2a-b). The roughness of the polyaniline layer-coated CSR becomes relatively smoother again after drop-casting Ab-N,S-GQD@AuNP-PAni to microscale order (Fig. 2c). A similar observation was noted in the corresponding AFM images, as presented in Fig. 2d-e. The CSR's rough surface due to the bare polyaniline becomes relatively smooth after nanoconjugates formation, following the same trend as the SEM images. The AuNP-PAni forms a nanowire structure, and the binding of N,S-GQDs onto AuNPs makes the electrode smoother after the coating of nanocomposite to cover the porous structure of polyaniline. When the AuNP-PAni was modified on CSR, electrical

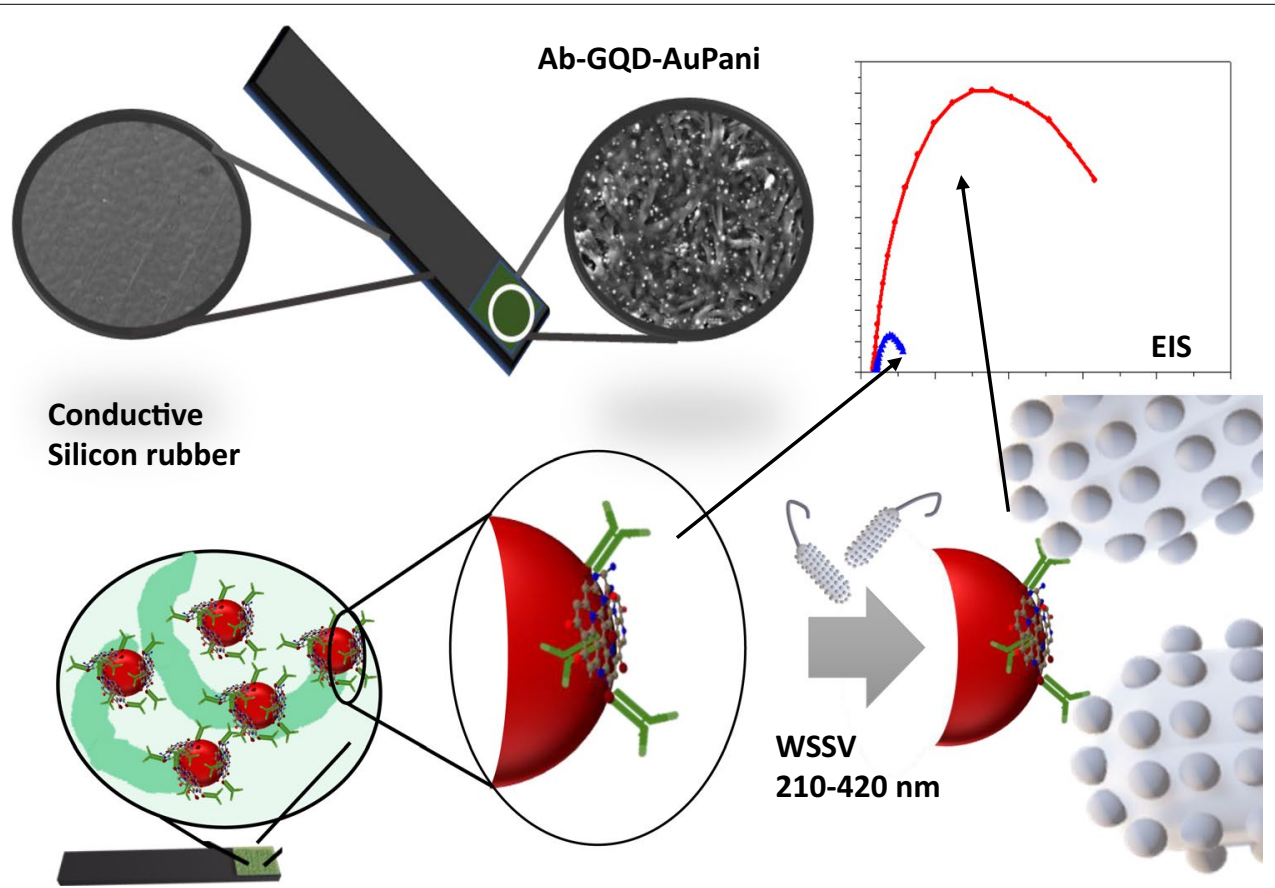

Scheme 1. Overview of a highly conductive disposable electrochemical electrode for the detection of WSSV 

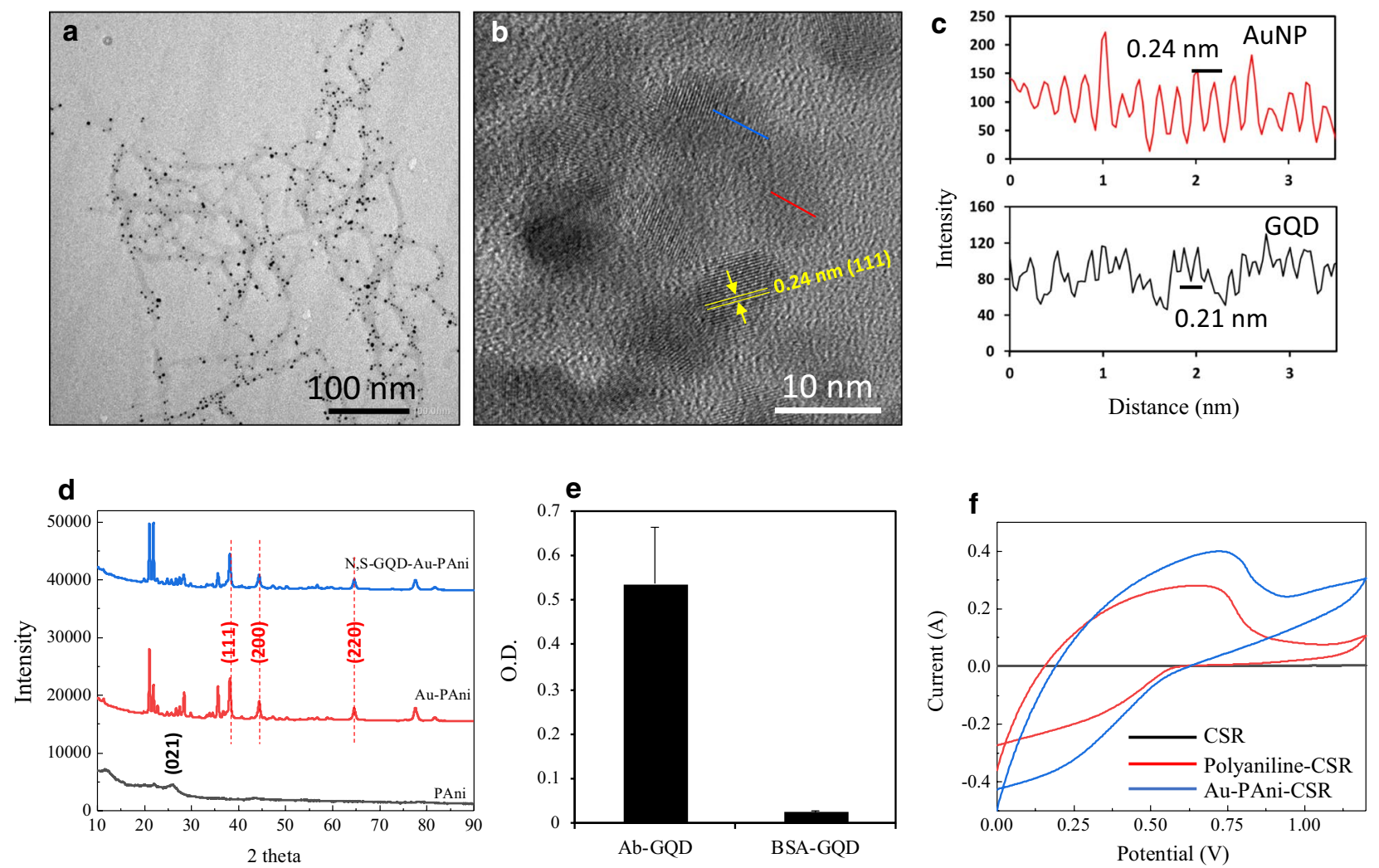

Fig. 1 Characterization of Ab-N,S-GQD@AuNP-PAni. (a) TEM image of AuNP-PAni, (b) HR-TEM image of the N,S-GQD-AuNP nanocomposite, and (c) fringe analysis using ImageJ. (d) Powder XRD analysis of silicon, PAni/CSR, AuNP-PAni/CSR, and N,S-GQD-AuNP-PAni/CSR. (e) ELISA of Ab-N,S-GQDs. (f) Cyclic voltammetry diagrams of CSR, polyaniline-CSR and AuNP-PAni/CSR

conductivity significantly improved compared with AuNPs-modified CSR (Additional file 1: Fig. S6). In this study, the electric resistance was used as an indicator, and it was shown that AuNPs are a suitable material for this purpose because they lead to higher conductivity by forming a complex with polyaniline nanowires.

After optimizing the PAni electropolymerization and thickness of the sensor electrode, the changes in the electrochemical properties were investigated by EIS. The conductivity and dielectric properties of the CSR surface gradually decreased after polyaniline and successive $\mathrm{Ab}$ N,S-GQD-AuNP-PAni conjugation (Fig. 2f), indicating successful formation of a sensor electrode suitable for virus detection.

Furthermore, the sensing area was optimized for virus detection. Electrodes with different sensor areas from 2 $\mathrm{mm}^{2}$ to $25 \mathrm{~mm}^{2}$ were prepared, and WSSV was detected by following the same procedure (Additional file 1: Fig. S7). The larger the sensor area was, the more remarkable the change in the Rct value. The sensing area's size indicates the size of the contact surface with the virus during the antigen-antibody reaction. It suggests that the larger the area is, the more virus that binds to the sensor.
On the other hand, the sensor with a large area has a low correlation coefficient $\left(R^{2}\right.$ value) and a high error range, particularly in the high concentration range. As the area increases, it is difficult to obtain uniformity between electrodes with simple modification by only dropping nanomaterials, resulting in a low $R^{2}$ value in virus detection. The electrode with a sensing area of 10 $\mathrm{mm}^{2}$, which gave the most reliable result, was used as the optimum detection electrode.

\section{Detection of WSSV}

The Nyquist impedance plots of the disposable electrode after incubation of different concentrations of the virus from $10^{2}-10^{9}$ copies $/ \mathrm{ml}$ are shown in Fig. 3A. The EIS responses of the sensor electrodes increase with the concentration of WSSV due to the high resistance accumulation between the virus-loaded nanocomposite and CSR. When WSSV binds to the sensing electrode, a large number of nonconducting virus particles cover the conducting surface of Ab-N,S-GQD@AuNP-PAni/ CSR, increasing the charge transfer resistance $\left(R_{c t}\right)$. The percentage change of the signal difference between the $R_{c t}$ values of the corresponding virus-loaded electrode 

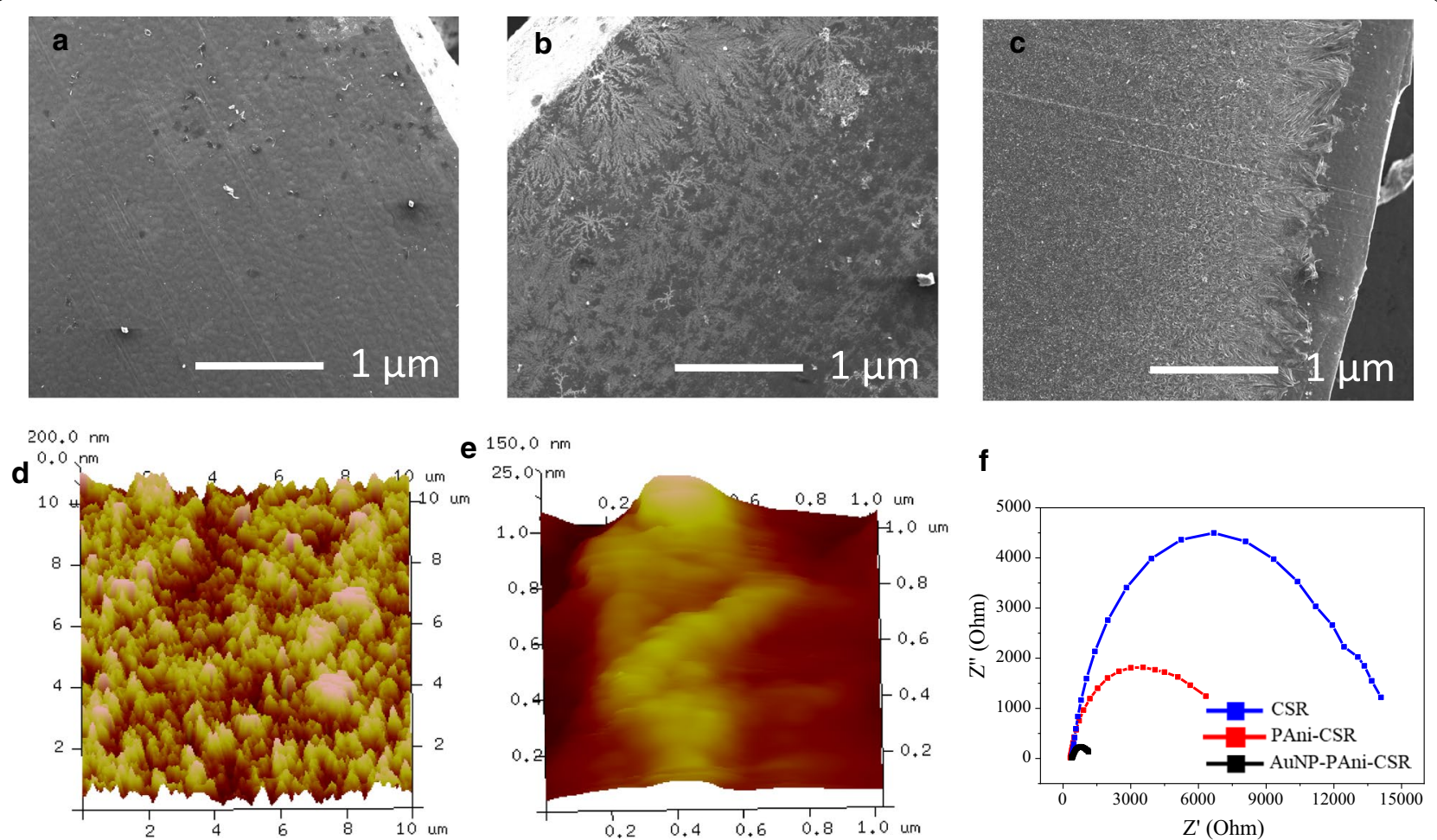

Fig. 2 Surface appearances of CSR, PAni/CSR, and AuNP-PAni/CSR. a-c SEM images and $\mathbf{d}-\mathbf{e}$ AFM images of CSR and AuNP-PAni/CSR, and $\mathbf{f}$ impedance Nyquist plot of CSR, PAni/CSR, and AuNP-PAni/CSR

and the bare electrode was adopted as the measurement signal. The calibration plot displays an excellent linear relationship between $\mathrm{R}_{\mathrm{ct}}$ and the WSSV concentration (Fig. 3b). The LOD was found as low as 48.4 copies/ $\mathrm{ml}$, calculated by $3 \sigma / \mathrm{S}$ (S is the slope of the linear calibration plot, and $\sigma$ is the unbiased standard deviation from the lowest signal of the detection result) [49]. This value is extremely low and sensitive enough to detect the real analyte [50]. After WSSV detection, the surface of the virus-loaded electrode exhibited a significantly increased roughness, indicating the presence of WSSV on the electrode (Additional file 1: Fig. S8).
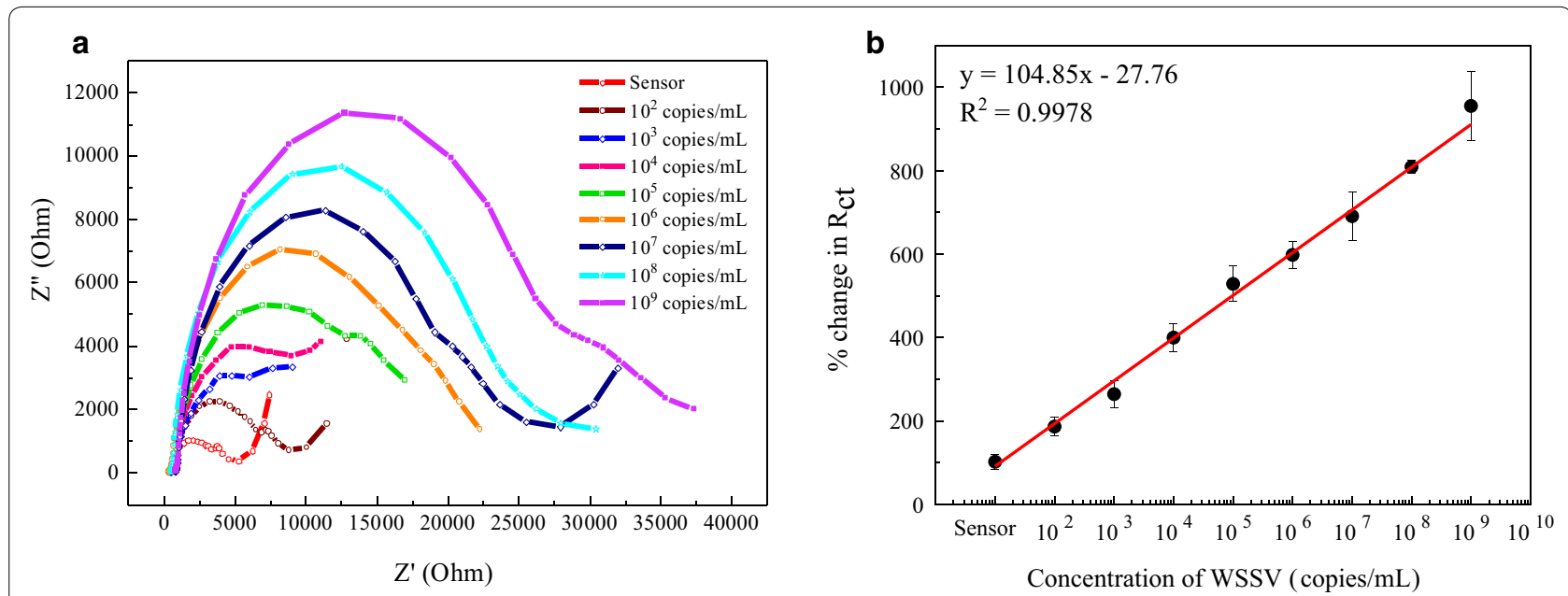

Fig. 3 WSSV detection using the disposable electrode. a Nyquist plots for different concentrations of WSSV in the range of $10^{2}-10^{9} \mathrm{DNA}$ copies/ml. b Calibration curve of the corresponding impedance. Each detection was performed three times and data are given as average $\pm \operatorname{SD}(n=3)$ 
Table 1 Comparison of the sensing performance of our proposed sensor with various WSSV detection methods

\begin{tabular}{|c|c|c|c|c|}
\hline Materials/Method of detection & Target virus (Analyte) & Detection range & LOD & Refs \\
\hline Piezoelectric microcantilever sensors & WSSV (DNA) & 50 to $10^{5}$ virions $/ \mathrm{ml}$ & 100 virions $/ \mathrm{ml}$ & [51] \\
\hline Lateral flow assay & WSSV (DNA) & 36-1784 viral copies/ng & 356 viral copies/ng & [52] \\
\hline Surface plasmon resonance & WSSV (Antigen) & 5 to $50 \mathrm{ng} / \mathrm{ml}$ & $2.5 \mathrm{ng} / \mathrm{ml}$ & [53] \\
\hline Loop-mediated isothermal amplification & WSSV (DNA) & 0.05 to $1 \mu \mathrm{g} /$ reaction (LAMP products) & $2 \times 10^{2}$ copies & [54] \\
\hline Electrochemical & WSSV (Antigen) & $1.37 \times 10^{-3}$ to $1.37 \times 10^{7}$ copies $/ \mu \mathrm{L}$ & $1.36 \times 10^{-3}$ copies $/ \mu \mathrm{l}$ & [22] \\
\hline Enzyme-linked immunosorbent assay & WSSV (Antigen) & $15-240$ ng/well & 250 pg/well & {$[55]$} \\
\hline Polymerase chain reaction & WSSV (DNA) & $9.0 \times 10^{1}-2.0 \times 10^{4}$ copies $/ \mu g$ & 4 copies/sample & [14] \\
\hline Impedance electrochemical detection & WSSV (Antigen) & $10^{2}$ to $10^{9}$ DNA copies $/ \mathrm{ml}$ & 48.4 DNA copies/ml & This work \\
\hline
\end{tabular}

We compared our sensing performance with various WSSV detection methods in Table 1 . Many studies have successfully detected DNA as the target analyte. However, it is not easy to implement on-site and rapid detection because of the need to extract DNA from the WSSV. On the other hand, antigen detection with high sensitivity has not been reported earlier, except for electrochemical methods. Our detection system is useful because it shows high sensitivity, simplicity, and adaptability for onsite detection.

\section{Selectivity and stability of the disposable electrode}

As the antibody directs the interaction between the analyte and the sensor electrode, the sensor should possess high selectivity. However, the specificity test of the sensor is still crucial for clarifying any possible cross-reactivity in real application. To confirm the specificity towards
WSSV, various other viruses and some materials were tested to the sensor electrode. The sensor responses, except for WSSV (Fig. 4a), were similar to that of the bare electrode, indicating the sensor specificity for the target virus. The high selectivity of the sensors was achieved by a close coating of Ab-N,S-GQD-AuNP-PAni and effective cleaning with PBST. When many foreign substances were present in the real matrix, and the non-specific adsorption occurred on the sensor surface, the substances other than the target WSSV were removed with a highly efficient washing solution. This led to high selectivity of our proposed detection method.

The effect of interferences on sensor's performance and recovery ratio of target analyte were also investigated [56, 57]. A fixed concentration of $10^{4}$ copies/ml WSSV was mixed with different matrixes and then similarly detected by the sensor electrode.
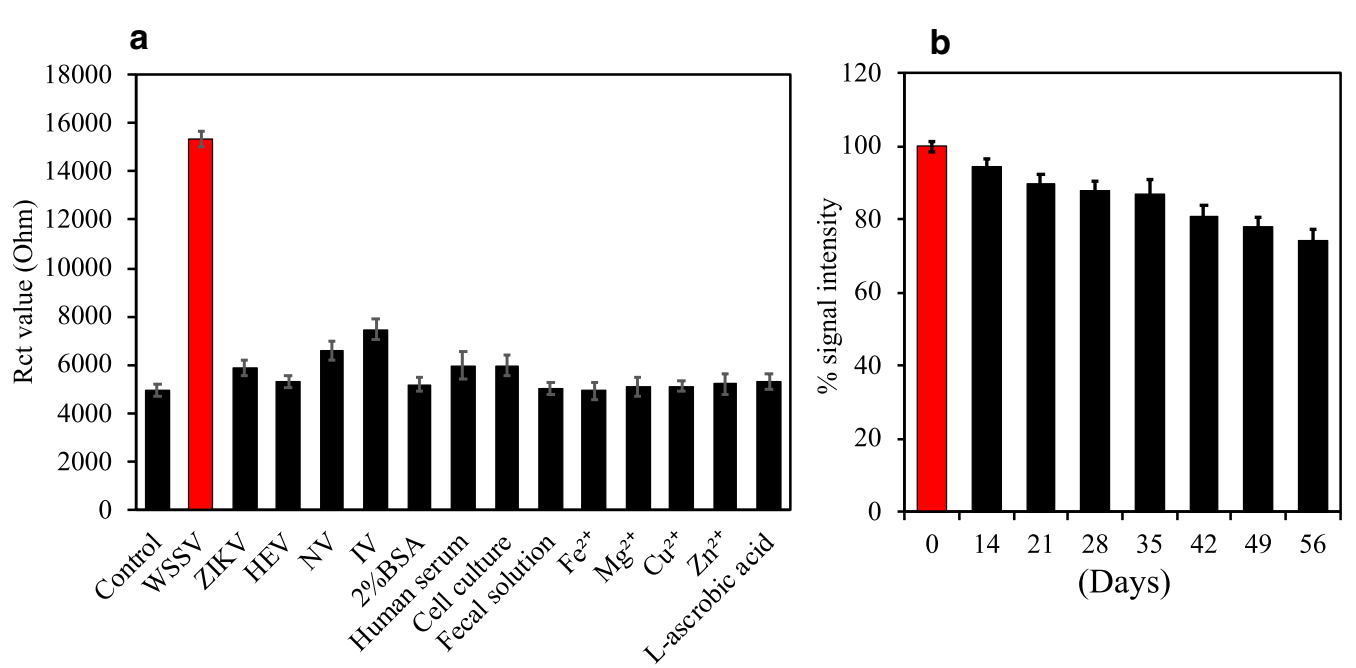

Fig. 4 a Selectivity test of Ab-N,S-GQD@AuNP-PAni/CSR for WSSV detection compared with nontarget viruses. The concentration of IFV and HEV used was $10 \mathrm{pg} / \mathrm{ml}$, while that of ZIKV and NoV was $10^{4} \mathrm{copies} / \mathrm{ml}$. Human serum used $100 \%$ in solution. Fecal solution indicates the supernatant of centrifuged solution $1 \mathrm{~g}$ of feces in $1 \mathrm{ml}$ of PBS buffer. Other ions and L-ascorbic acid were prepared to $1 \mathrm{mM}$. $\mathbf{b}$ Stability test of the disposable electrode. The electrode was stored in the refrigerator for 56 days, and the detection performance was investigated every week from the $2 n d$ week. The Rct value on the first day was set to $100 \%$ 
Table 2 Detection of WSSV in various interferences

\begin{tabular}{lllll}
\hline Suspension $^{\mathbf{a}}$ & $\begin{array}{l}\text { Average } \\
\text { Rct } \\
\text { value }^{\mathbf{b}}\end{array}$ & $\begin{array}{l}\text { Concentration } \\
\text { by Rct (copies/ } \\
\mathbf{m l}^{\mathbf{c}}\end{array}$ & $\begin{array}{l}\text { Recovery } \\
\text { ratio (\%) }\end{array}$ & $\begin{array}{l}\text { Relative } \\
\text { error } \\
\mathbf{( \% )}^{\mathbf{e}}\end{array}$ \\
\hline PBS & 15,833 & $10,915.0$ & 109.2 & \pm 2.4 \\
$\begin{array}{l}\text { L-ascorbic acid } \\
(1 \mathrm{mM})\end{array}$ & 15,244 & $10,987.2$ & 109.9 & \pm 3.8 \\
$\mathrm{Fe}^{2+}(1 \mathrm{mM})$ & 15,784 & $11,577.6$ & 110.8 & \pm 4.2 \\
$\mathrm{Mg}^{2+}(1 \mathrm{mM})$ & 15,484 & $9,187.9$ & 91.9 & \pm 3.8 \\
$\mathrm{Cu}^{2+}(1 \mathrm{mM})$ & 15,662 & $12,523.3$ & 125.2 & \pm 2.9 \\
$\mathrm{Zn}^{2+}(1 \mathrm{mM})$ & 15,422 & 8512.7 & 88.1 & \pm 3.3 \\
\hline
\end{tabular}

a WSSV concentration in suspension is $10^{4}$ copies $/ \mathrm{ml}$

${ }^{b}$ Average Rct value of WSSV detection $(n=3)$

c WSSV concentration was calculated using the calibration curve (Fig. 3b)

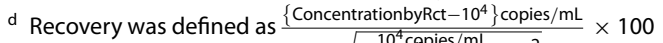
e Recovery error was defined as $\sqrt{\frac{1}{n-1} \sum_{k=1}^{10^{4} \text { cqpies/mL }}\left(x_{i}-\bar{x}\right)^{2}}$, where $x_{i}$ and $\bar{x}$ denote Rct
and average Rct values $(\mathrm{n}=3)$, respectively

The concentration of the recovered WSSV was calculated using a calibration curve (Fig. 3b) based on the obtained Rct values. The recovery ratio was compared, as shown in Table 2. When the WSSV was in PBS, $\mathrm{L}$-ascorbic acid, $\mathrm{Fe}^{2+}$, and $\mathrm{Cu}^{2+}$ ions, the recovery ratio was almost $110 \%$, while in case of $\mathrm{Mg}^{2+}$ and $\mathrm{Zn}^{2+}$, it was $90 \%$. These results indicate that some ions affect sensing performance with a standard deviation of $\pm 13 \%$. There was around $4 \%$ error in the recovery ratio, indicating that this system shows reasonable performances even in real matrix samples.

The stability of the disposable electrode was tested for 8 weeks to observe its applicability for long-term usage. As depicted in Fig. 4b, the signal intensity of Rct after loading of $10^{4}$ copies/ml virus remained at $86 \%$ until
35 days. However, it dropped to $73.4 \%$ after 56 days of storage due to degradation of the antibody.

To extend its application to other types of analytes, we prepared two different electrodes conjugated with different anti-HEV and anti-HA antibodies and detected their corresponding target viruses. These results demonstrate that the Nyquist impedance in both cases increases with increasing virus concentration (Additional file 1: Fig. S9A and B), and their corresponding calibration lines show excellent linearity (Additional file 1: Fig. S10A and B). The limit of detection was calculated as 34.6 DNA copies/ml for G3 HEV and $0.98 \mathrm{fg} / \mathrm{ml}$ for influenza virus A.

\section{Real virus analysis}

After successful detection of WSSV in a buffer medium, real samples were collected from $10 \mathrm{WSSV}$ infected shrimp and tested with the sensor. Their DNA copy numbers were compared with the results obtained from this electrochemical detection technique. The detection results are summarized in Table 3 and Fig. 5a. According to the RT-PCR data, sample Nos. 2 and 4 do not contain any WSSV, showing 2.4 and 6.5 copies $/ \mathrm{ml}$ according to our electrochemical method, and can be ignored. The electrochemical detection results for sample Nos. 8 and 9 significantly deviate from the RT-PCR results. However, the overall trend of the RT-PCR results for the samples shows excellent similarity to the trend of the electrochemical sensor results, confirming the reproducibility of the sensor. In the western blot analysis, the virus titer above $10^{7}$ copies $/ \mathrm{ml}$ shows VP-28 protein bands at approximately $22 \mathrm{kDa}$, but less than $10^{7}$ copies $/ \mathrm{ml}$

Table 3 Details of the detection results for real sample detection using the electrochemical method and RT-PCR

\begin{tabular}{|c|c|c|c|c|c|}
\hline \multirow[t]{2}{*}{ Sample no } & \multirow[t]{2}{*}{$R_{c t}$ value $\pm S D(n=3)$} & \multicolumn{2}{|c|}{ WSSV concentration (DNA copies/ml) } & \multirow[t]{2}{*}{ VP28 detection } & \multirow[t]{2}{*}{ Shrimp } \\
\hline & & by EIS ${ }^{a}$ & by RT-PCR & & \\
\hline Control & $2680 \pm 146$ & 0 & - & & \\
\hline 1 & $7179 \pm 238$ & $4.8 \times 10^{3}$ & $1.2 \times 10^{5}$ & No & Live \\
\hline 2 & $2797 \pm 72$ & $2.4 \times 10^{0}$ & 0 & No & Live \\
\hline 3 & $8988 \pm 108$ & $2.0 \times 10^{4}$ & $6.2 \times 10^{5}$ & No & Dead \\
\hline 4 & $4572 \pm 143$ & $6.5 \times 10^{0}$ & 0 & No & Live \\
\hline 5 & $12,101 \pm 490$ & $2.6 \times 10^{5}$ & $8.4 \times 10^{7}$ & No & Dead \\
\hline 6 & $16,946 \pm 406$ & $1.4 \times 10^{7}$ & $9.6 \times 10^{8}$ & Yes & Dead \\
\hline 7 & $26,949 \pm 140$ & $4.7 \times 10^{10}$ & $2.2 \times 10^{10}$ & Yes & Dead \\
\hline 8 & $18,946 \pm 893$ & $6.9 \times 10^{7}$ & $7.5 \times 10^{9}$ & Yes & Dead \\
\hline 9 & $22,308 \pm 195$ & $1.0 \times 10^{9}$ & $3.5 \times 10^{8}$ & Yes & Dead \\
\hline 10 & $13,988 \pm 406$ & $1.2 \times 10^{6}$ & $2.4 \times 10^{8}$ & Yes & Dead \\
\hline
\end{tabular}

\footnotetext{
${ }^{a}$ The copy number of WSSV was determined from the calibration line (Fig. $3 C$ ) using the measured $R_{c t}$ value
} 

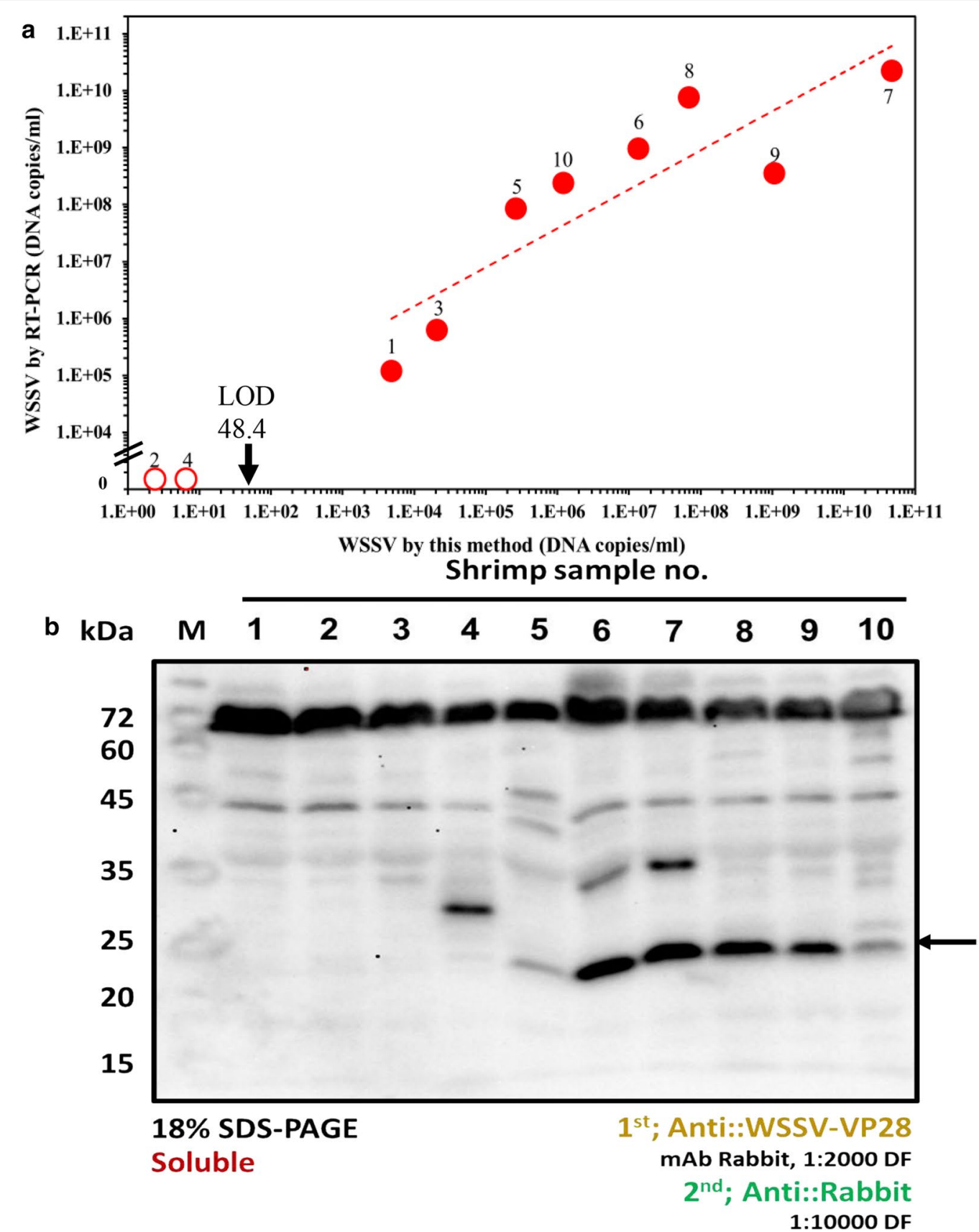

Fig. 5 a Comparison of electrochemical detection and RT-PCR methods. The open circles (opened circle) indicate a negative and the red circles (closed circle) a positive result as judged by the RT-PCR result. The arrow indicates the limit of detection. $\mathbf{b}$ Western blot analysis of WSSV-VP28 from shrimp samples using anti-VP28 antibody as a primary antibody. The arrow indicates VP-28

could not be detected (Fig. 5b). This indicates that our sensing system shows a 6-7 order of magnitude higher sensitivity than western blot. This method, which can detect WSSV from specimens in less than $20 \mathrm{~min}$, is much faster than the time-consuming RT-PCR, which is currently used as a gold standard. Although the correlation coefficient between the two methods is $90 \%$, the developed method can be used to judge WSSV infection in a short time with easy handling.

\section{Conclusion}

A disposable electrode consisting of an Ab-N,S-GQD@ AuNP-PAni nanocomposite on a CSR electrode was fabricated in this work for the rapid and sensitive detection 
of WSSV within $20 \mathrm{~min}$. This disposable sensor showed a low Rct value in the impedance spectrum as a bare sensor, which significantly increased with the target virus concentration over a wide linear range from $10^{2}$ to $10^{9}$ DNA copies $/ \mathrm{ml}$, with a LOD of 48.4 copies $/ \mathrm{ml}$. The proposed disposable electrode's applicability was successfully demonstrated, with high selectivity and long-term stability of 5 weeks. The sensing capability was also tested for other viruses, indicating its versatile applicability for future usage. The sensor was applied to detect the real WSSV from WSSV-infected shrimp in aquaculture and found to be comparable with RT-PCR analysis, which confirmed its applicability as an excellent monitoring system for real-time virus detection. This detection system will play an essential role in controlling the spread of WSSV for on-site detection systems at shrimp farms that do not have adequate testing facilities.

\section{Supplementary information}

Supplementary information accompanies this paper at https://doi. org/10.1186/s12951-020-00712-4.

Additional file 1: Figure S1 Analysis of functional groups on the surface of named materials by FT-IR infrared absorption spectra. Figure $\mathbf{S 2}$. Impedance analysis of the PAni-PAni/CSR sensor electrode after 5 to 20 cycles of electrodeposition. Figure $\mathbf{S 3}(\mathrm{A}-\mathrm{C})$ The difference in thickness of the polyaniline layer deposited on CSR was observed by SEM. Figure S4. Cyclic voltammetry analysis of the Ab-N,S-GQD@AuNP-PAni-PAni/CSR sensor electrode after 2 to 50 cycles. Figure S5. Cyclic voltammetry of CSR day1 (black line) and day2 (red line). Figure S6. Comparison of the Rct values for AuNP-coated CSR (blue line) and AuNP/PAni-coated CSR (orange line). Figure S7. Detection result of WSSV using different surface areas of Ab-N,S-GQD@AuNP-PAni-PAni/CSR. Figure S8. AFM images of the bare disposable sensor electrode (A) and WSSV-bound electrode (B). Figure S9. Nyquist impedance plots of the Ab-N,S-GQD@AuNP-PAni-PAni/CSR sensor electrode before and after loading A) HEV and B) influenza virus. Figure S10. Detection results of genotype $3 \mathrm{HEV}$ (A) and influenza virus A ( $\mathrm{H} 1 \mathrm{~N} 1$ ) (B) using the Ab-N,S-GQD@AuNP-PAni/CSR sensor electrode with their corresponding antibodies attached.

\section{Acknowledgments}

We thank Dr. Tian-Cheng Li of the National Institute of Infectious Diseases (Japan) for providing HEV, rabbit anti-G3 HEV IgG antibody, and NoV-LP. We also appreciate Professor Kouichi Morita of the Institute of Tropical Medicine, Nagasaki University (Japan) for kindly providing ZIKV (strain PRVABC-59).

\section{Authors' contributions}

KT performed the sensor design and experiment, data analysis, and writing of the manuscript draft. JS provided the WSSV-infected shrimp and performed data validation. JB performed sample pretreatment and western blotting. SP performed AFM imaging and data validation. ADC contributed to the manuscript preparation, data validation and revision of the manuscript. EYP supervised, funded, and revised the manuscript. All authors read and approved the final manuscript.

\section{Funding}

This work was supported by the Yanmar environmental sustainability support association (YESSA).

\section{Availability of data and materials}

All data generated or analyzed during this study are included in this manuscript and its additional information.
Ethics approval and consent to participate Not applicable.

\section{Consent for publication}

Not applicable.

\section{Competing interests}

The authors declare that they have no competing interests.

\section{Author details}

1 Laboratory of Biotechnology, Department of Bioscience, Graduate School of Science and Technology, Shizuoka University, 836 Ohya, Suruga-ku, Shizuoka 422-8529, Japan. ${ }^{2}$ Division of Pathology, Department of Aquaculture Research, Fisheries Technology Institute of Japan Fisheries Research and Education Agency, National Research and Development Agency, Tamaki Field Station, 224-1 Hiruta, Tamaki, Watarai, Mie 519-0423, Japan. ${ }^{3}$ Division of Cardiovascular Diseases, Mayo Clinic College of Medicine and Science, Mayo Clinic, 200 First Street SW, Rochester, MN 55905, USA. ${ }^{4}$ Laboratory of Biotechnology, Research Institute of Green Science and Technology, Shizuoka University, 836 Ohya, Suruga-ku, Shizuoka 422-8529, Japan.

Received: 13 August 2020 Accepted: 17 October 2020

Published online: 27 October 2020

References

1. Lo C-F, Ho CH, Peng SE, Chen CH, Hsu HC, Chiu YL, et al. White spot syndrome baculovirus (WSBV) detected in cultured and captured shrimp, crabs and other arthropods. Dis Aquat Organ. 1996;27:215-25.

2. Cai S, Huang J, Wang C, Song X, Sun X, Yu J, et al. Epidemiological studies on the explosive epidemic disease of prawn in 1993-1994. J Fish China. 1995:19:112-9.

3. Lo C-F, Kou G-H. Virus-associated white spot syndrome of shrimp in Taiwan: a review. Fish Pathol. 1998;33:365-71.

4. Rajendran K, Vijayan K, Santiago T, Krol R. Experimental host range and histopathology of white spot syndrome virus (WSSV) infection in shrimp, prawns, crabs and lobsters from India. J Fish Dis. 1999;22:183-91.

5. Kalaimani N, Ravisankar T, Chakravarthy N, Raja S, Santiago T, Ponniah A. Economic losses due to disease incidences in shrimp farms of India. Fish Technol. 2013;50:80-6.

6. Wang Y-C, Lo C-F, Chang P-S, Kou G-H. Experimental infection of white spot baculovirus in some cultured and wild decapods in Taiwan. Aquaculture. 1998;164:221-31.

7. Witteveldt J, Cifuentes CC, Vlak JM, van Hulten MC. Protection of Penaeus monodon against white spot syndrome virus by oral vaccination. J Virol. 2004;78:2057-61.

8. Taengchaiyaphum S, Nakayama H, Srisala J, Khiev R, Aldama-Cano DJ, Thitamadee $S$, et al. Vaccination with multimeric recombinant VP28 induces high protection against white spot syndrome virus in shrimp. Dev Comp Immunol. 2017;76:56-64.

9. Witteveldt J, Vlak JM, van Hulten MC. Protection of Penaeus monodon against white spot syndrome virus using a WSSV subunit vaccine. Fish Shellfish Immunol. 2004;16:571-9.

10. Hsu H-C, Lo C-F, Lin S-C, Liu K-F, Peng S-E, Chang Y-S, et al. Studies on effective PCR screening strategies for white spot syndrome virus (WSSV) detection in Penaeus monodon brooders. Dis Aquat Organ. 1999;39:13-9.

11. Nunan LM, Lightner DV. Optimized PCR assay for detection of white spot syndrome virus (WSSV). J Virol Methods. 2011;171:318-21.

12. Nunan $L M$, Lightner DV. Development of a non-radioactive gene probe by PCR for detection of white spot syndrome virus (WSSV). JVirol Methods. 1997;63:193-201.

13. Yan D-C, Dong S-L, Huang J, Yu X-M, Feng M-Y, Liu X-Y. White spot syndrome virus (WSSV) detected by PCR in rotifers and rotifer resting eggs from shrimp pond sediments. Dis Aquat Organ. 2004;59:69-73.

14. Durand S, Lightner DV. Quantitative real time PCR for the measurement of white spot syndrome virus in shrimp. J Fish Dis. 2002;25:381-9.

15. Dai H, Gao H, Zhao X, Dai L, Zhang X, Xiao N, et al. Construction and characterization of a novel recombinant single-chain variable fragment antibody against white spot syndrome virus from shrimp. J Immunol Methods. 2003;279:267-75. 
16. Zhan WB, Wang YH, Fryer JL, Okubo K, Fukuda H, Yu KK, et al. Production of monoclonal antibodies (MAbs) against white spot syndrome virus (WSSV). J Aquat Anim Health. 1999;11:17-22.

17. Kulabhusan PK, Rajwade JM, Hameed AS, Paknikar KM. Lateral flow assay for rapid detection of white spot syndrome virus (WSSV) using a phagedisplayed peptide as bio-recognition probe. Appl Microbiol Biotechnol. 2017:101:4459-69.

18. Kulabhusan PK, Rajwade JM, Sugumar V, Taju G, Hameed AS, Paknikar KM. Field-usable lateral flow immunoassay for the rapid detection of white spot syndrome virus (WSSV). PLoS ONE. 2017;12:e0169012.

19. Tang X, Liang Q, Liu L, Sheng X, Xing J, Zhan W. An optimized doubleantibody sandwich ELISA for quantitative detection of WSSV in artificially infected crayfish. J Virol Methods. 2018;251:133-8.

20. Sithigorngul W, Rukpratanporn S, Pecharaburanin N, Longyant S, Chaivisuthangkura P, Sithigorngul P. A simple and rapid immunochromatographic test strip for detection of white spot syndrome virus (WSSV) of shrimp. Dis Aquat Organ. 2006;72:101-6.

21. Waiwijit U, Phokaratkul D, Kampeera J, Lomas T, Wisitsoraat A, Kiatpathomchai W, et al. Graphene oxide based fluorescence resonance energy transfer and loop-mediated isothermal amplification for white spot syndrome virus detection. J Biotechnol. 2015;212:44-9.

22. Natarajan A, Devi KS, Raja S, Kumar AS. An elegant analysis of white spot syndrome virus using a graphene oxide/methylene blue based electrochemical immunosensor platform. Sci Rep. 2017:7:46169.

23. Jain PK, Huang X, El-Sayed IH, El-Sayed MA. Review of some interesting surface plasmon resonance-enhanced properties of noble metal nanoparticles and their applications to biosystems. Plasmonics. 2007;2:107-18.

24. Lee J, Takemura K, Park E. Plasmonic nanomaterial-based optical biosensing platforms for virus detection. Sensors. 2017;17:2332.

25. Tian Y, Deng P, Wu Y, Li J, Liu J, Li G, et al. MnO2 nanowires-decorated reduced graphene oxide modified glassy carbon electrode for sensitive determination of bisphenol A. J Electrochem Soc. 2020;167:046514.

26. He Q, Liu J, Liu X, Li G, Deng P, Liang J. Preparation of Cu2O-reduced graphene nanocomposite modified electrodes towards ultrasensitive dopamine detection. Sensors. 2018:18:199.

27. Wu Y, Deng P, Tian Y, Feng J, Xiao J, Li J, et al. Simultaneous and sensitive determination of ascorbic acid, dopamine and uric acid via an electrochemical sensor based on PVP-graphene composite. J Nanobiotech. 2020;18:1-13.

28. Li G, Xia Y, Tian Y, Wu Y, Liu J, He Q, et al. Recent developments on graphene-based electrochemical sensors toward nitrite. J Electrochem Soc. 2019;166:B881.

29. Lee J, Morita M, Takemura K, Park EY. A multi-functional gold/iron-oxide nanoparticle-CNT hybrid nanomaterial as virus DNA sensing platform. Biosens Bioelectron. 2018;102:425-31.

30. Sepunaru L, Plowman BJ, Sokolov SV, Young NP, Compton RG. Rapid electrochemical detection of single influenza viruses tagged with silver nanoparticles. Chem Sci. 2016;7:3892-9.

31. Dick JE, Hilterbrand AT, Boika A, Upton JW, Bard AJ. Electrochemical detection of a single cytomegalovirus at an ultramicroelectrode and its antibody anchoring. Proc Natl Acad Sci. 2015;112:5303-8.

32. Chowdhury AD, Takemura K, Li TC, Suzuki T, Park EY. Electrical pulseinduced electrochemical biosensor for hepatitis E virus detection. Nat Commun. 2019;10:3737.

33. Chowdhury AD, Den A, Chaudhuri CR, Bandyopadhyay K, Sen P. Label free polyaniline based impedimetric biosensor for detection of E. coli O157: H7 Bacteria. Sens Actuators B Chem. 2012;171:916-23.

34. Chowdhury AD, Gangopadhyay R, De A. Highly sensitive electrochemical biosensor for glucose, DNA and protein using gold-polyaniline nanocomposites as a common matrix. Sens Actuat B Chem. 2014;190:348-56.

35. Park S, Hwang IW, Makishima Y, Perales-Clemente E, Kato T, Niederländer $\mathrm{NJ}$, et al. Spot14/Mig12 heterocomplex sequesters polymerization and restrains catalytic function of human acetyl-CoA carboxylase 2. J Mol Recognit. 2013;26:679-88.

36. Ganganboina AB, Doong R-A. Graphene quantum dots decorated goldpolyaniline nanowire for impedimetric detection of carcinoembryonic antigen. Sci Rep. 2019;9:1-11.

37. Raghav R, Srivastava S. Immobilization strategy for enhancing sensitivity of immunosensors: L-asparagine-AuNPs as a promising alternative of EDC-NHS activated citrate-AuNPs for antibody immobilization. Biosens Bioelectron. 2016;78:396-403.
38. Satoh J, Nishizawa T, Yoshimizu M. Protection against white spot syndrome virus (WSSV) infection in kuruma shrimp orally vaccinated with WSSV rVP26 and rVP28. Dis Aquat Organ. 2008:82:89-96.

39. Boonyakida J, Xu J, Satoh J, Nakanishi T, Mekata T, Kato T, et al. Antigenic properties of VP15 from white spot syndrome virus in kuruma shrimp Marsupenaeus japonicus. Fish Shellfish Immunol. 2020;101:152-8.

40. He Q, Liu J, Liu X, Li G, Chen D, Deng P, et al. Fabrication of amine-modified magnetite-electrochemically reduced graphene oxide nanocomposite modified glassy carbon electrode for sensitive dopamine determination. Nanomaterials. 2018;8:194.

41. Tian Y, Deng P, Wu Y, Liu J, Li J, Li G, et al. High sensitive voltammetric sensor for nanomolarity vanillin detection in food samples via manganese dioxide nanowires hybridized electrode. Microchem J. 2020;104:885.

42. Wu Y, Deng P, Tian Y, Ding Z, Li G, Liu J, et al. Rapid recognition and determination of tryptophan by carbon nanotubes and molecularly imprinted polymermodified glassy carbon electrode. Bioelectrochem. 2020;131:107393.

43. Torres-Mendieta R, Ventura-Espinosa D, Sabater S, Lancis J, Mínguez-Vega G, Mata JA. In situ decoration of graphene sheets with gold nanoparticles synthetized by pulsed laser ablation in liquids. Sci Rep. 2016;6:30478.

44. Dutta Chowdhury A, Doong R. Highly sensitive and selective detection of nanomolar ferric ions using dopamine functionalized graphene quantum dots. ACS Appl Mater Interfaces. 2016;8:21002-10.

45. Dave K, Park KH, Dhayal M. Characteristics of ultrasonication assisted assembly of gold nanoparticles in hydrazine reduced graphene oxide. RSC Adv. 2015;5:107348-54.

46. Berzina T, Pucci A, Ruggeri G, Erokhin V, Fontana MP. Gold nanoparticles-polyaniline composite material: Synthesis, structure and electrical properties. Synth Met. 2011;161:1408-13.

47. Cai A, Wang Q, Chang Y, Wang X. Graphitic carbon nitride decorated with $\mathrm{S}, \mathrm{N}$ co-doped graphene quantum dots for enhanced visible-light-driven photocatalysis. J Alloys Compd. 2017;692:183-9.

48. Mirmohseni A, Solhjo R. Preparation and characterization of aqueous polyaniline battery using a modified polyaniline electrode. Eur Polym J. 2003;39:219-23.

49. Takemura K, Adegoke O, Takahashi N, Kato T, Li T-C, Kitamoto N, et al. Versatility of a localized surface plasmon resonance-based gold nanoparticle-alloyed quantum dot nanobiosensor for immunofluorescence detection of viruses. Biosens Bioelectron. 2017:89:998-1005.

50. Adegoke O, Morita M, Kato T, Ito M, Suzuki T, Park EY. Localized surface plasmon resonance-mediated fluorescence signals in plasmonic nanoparticle-quantum dot hybrids for ultrasensitive Zika virus RNA detection via hairpin hybridization assays. Biosens Bioelectron. 2017;94:513-22.

51. Capobianco JA, Shih W-H, Leu J-H, Lo GC, Shih WY. Label free detection of white spot syndrome virus using lead magnesium niobate-lead titanate piezoelectric microcantilever sensors. Biosens Bioelectron. 2010;26:964-9.

52. Powell JW, Burge EJ, Browdy CL, Shepard EF. Efficiency and sensitivity determination of Shrimple ${ }^{\circledR}$, an immunochromatographic assay for white spot syndrome virus (WSSV), using quantitative real-time PCR. Aquaculture. 2006;257:167-72.

53. Lei Y, Chen H, Dai H, Zeng Z, Lin Y, Zhou F, et al. Electroless-plated gold films for sensitive surface plasmon resonance detection of white spot syndrome virus. Biosens Bioelectron. 2008;23:1200-7.

54. Seetang-Nun Y, Jaroenram W, Sriurairatana S, Suebsing R, Kiatpathomchai W. Visual detection of white spot syndrome virus using DNA-functionalized gold nanoparticles as probes combined with loop-mediated isothermal amplification. Mol Cell Probes. 2013;27:71-9.

55. Murugan V, Sankaran K. Bacterial lipid modification of ICP 11 and a new ELISA system applicable for WSSV infection detection. Mar Biotechnol. 2018;20:375-84.

56. He Q, Tian Y, Wu Y, Liu J, Li G, Deng P, et al. Facile and ultrasensitive determination of 4-nitrophenol based on acetylene black paste and graphene hybrid electrode. Nanomaterials. 2019;9:429.

57. He Q, Wu Y, Tian Y, Li G, Liu J, Deng P, et al. Facile electrochemical sensor for nanomolar rutin detection based on magnetite nanoparticles and reduced graphene oxide decorated electrode. Nanomaterials. 2019;9:115.

\section{Publisher's Note}

Springer Nature remains neutral with regard to jurisdictional claims in published maps and institutional affiliations. 